\title{
Assessment of Technological Innovation Climate in Organizations
}

\author{
Refaat Hassan Abdel-Razek ${ }^{1}$, Fawzah Battal Alharbi ${ }^{2}$ \\ ${ }^{1}$ Professor of Engineering Management, College of Engineering, \\ University of Sharjah, Department of Industrial Engineering \& Engineering Management, \\ Sharjah, United Arab Emirates \\ rabdelrazek@sharjah.ac.ae \\ ${ }^{2}$ Graduate of Dept. of Technology \& Innovation Management, \\ College of Graduate Studies, Arabian Gulf University, Bahrain
}

\begin{abstract}
The ability to develop a work environment climate supporting technological innovation does not occur suddenly or unexpectedly. The objectives of this paper is to assess the technological innovation climate in one of the largest oil and gas company in the world, to compare the results with published standards, and to suggest recommendations to improve the innovation climate in the company. The study used the situational outlook questionnaire to assess nine key dimensions of innovation climate. The results showed that the extent to which each of the nine dimensions is applied were: debate (70\%); idea support (67\%); challenge/involvement (67\%); trust and openness (59\%); freedom (57\%); idea time (56\%); playfulness/humor (52\%); risk taking $(50 \%)$ and conflict $(46 \%)$. These results were compared with published norms and the results revealed that the company is categorized as innovative in debate, idea time, idea support and trust; categorized as average in challenge and risk taking; and as stagnated in freedom, playfulness and conflict. The comparison using the t-test confirmed the results. Recommendations and details of the actions required for improvement were outlined.
\end{abstract}

Keywords. Creativity, Innovation Assessment, Innovation Climate, Innovation Culture, Innovation Management.

\section{Introduction}

Improving work environment in organizations by buying comfortable furniture and luxurious offices are not making innovation or enhance the stuff creativity. The most important factor as proposed by Parther (2010) is "establishing a climate for innovation". A research by PricewaterhouseCoopers (2007) examined the gaps between the most innovative companies and the lowest performance from among the Times Top 1000 organizations in the United Kingdom. The study identified three basic capabilities that characterized the more successful organizations: having a deliberate process for idea management, building a creative climate and following an inclusive approach to leadership. A report made by UNESCO (2010) stated that even oil-richArab states need innovation. Despite the need for innovation, the literature shows that oil-rich-Arab states lag far behind developed countries in terms of science and technology (Sanyal \& Varghese, 2006; UNESCO, 2010). Abdel-Razek and Alsanad 
(2014) stated that all developing countries fall far behind developed countries in terms of technology and innovation. Abdel-Razek and Alsanad (2015) showed that progress in modern technology is the only way for developing countries to join the league of developed countries. Alabbas and Abdel-Razek (2016) emphasized the importance of the evaluation and improvement of creativity and environment climate in organizations in order to improve their innovation and consequently their technology. Abdel-Razek (2014) and Alsanad and Abdel-Razek (2016) demonstrated that there is little current published literature that investigates the several research areas of innovation including the assessment and methods of improvement of creative and innovation climate in organizations in developing countries generally and in the Arab countries specifically.

Climate can be defined as the recurring patterns of behavior, attitude and feeling that characterize life in the organization (Tidd and Bessant, 2013). Climate of innovation and creativity is the climate that supports the development, assimilation and utilization of new and different approaches, practices and concepts. It is also the climate which promotes the generation, consideration and use of new products, services, and ways of working (Isaksen and Tidd, 2006). Early creativity research focused on individual characteristic that predisposed people to achieve high levels of creativity while more recent research has considered the effects of environment on individuals' ability to be creative (Adolfsson, et al. 2013). The most innovative companies of the future will be those, which have created the appropriate cultures and climates.

The objectives of this paper is to assess the technological innovation and creativity climate in the largest oil and gas organizations in the middle east, and one of the largest in the world, to compare the results with published standards, and to suggest recommendations to improve the innovation climate in the company.

\section{Dimensions of Innovation Climate}

Amabile, et al. (1999) categorized the innovation climate into four dimensions: management practices; organizational motivation; resources; and outcomes. McAlindon (2004) defined the characteristics that can be used to measure the innovation climate as: risk-taking, rewards, empowering, objective measurement, feedback, turbulence, interdependence, decentralization and cosmopolitan. Hoe (2011) discussed and proposed the factors to be useful in determining an organization innovation's climate as: shared vision, management support, community, individual creativity, implementation and motivators. Hunter, et al. (2005) claimed that there are more than 40 different conceptions of innovation climate and ways of assessing it. Hunter et al. (2007) in their analysis of 42 studies on the climate of creativity and innovation found that the studies that are based on a well-developed standardized instruments provides noticeable and stronger effects, than did the studies based on locally developed instrument. Tidd and Bessant (2009) stated six critical dimensions that influence the climate of innovation: trust and openness; challenge and involvement; support and space for ideas; conflict and debate; risk taking; and freedom. 


\section{The Research Tool}

There are a number of surveys and approaches to assess the organization climate for innovation. Mathisen and Einarsen (2004) conducted a survey for the best known and most used tools to asses innovation climate in organizations and reported four tools: the siegel scale of support of innovation (SSSI) (Siegel and Kaemmerer, 1978); team climate inventory (TCI) (Anderson and West, 1996); assessing the climate for creativity KEYS, originally called the work environment survey (Amabile, et al. 1999); and the situational outlook questionnaire (SOQ) (Isaksen, et al. 1999). These tools were critically reviewed. SSSI and TCI are not considered as tools for assessing technological innovation climate; KEYS needs more revision and more studies to assess its validity (Mathisen and Einarsen, 2004); and SOQ measures the perceptions of employees of the climate for creativity, innovation and their readiness for change within their immediate work environment. In addition, Isaksen and Ekvall, (2013) reported that the reliability of the SOQ was examined using a sample of 3491 individuals from fifty-two different organizations and they stated that the results of Cronbach alpha for the all the nine dimensions of innovation climate have greater than 0.70 values of alpha, which indicate acceptable levels of reliability.

In this research, the SOQ was selected as the instrument for this research and obtained the approval from Creative Problem solving Group, Inc. (CPSB) to use the (SOQ). The survey questionnaire consists of 53 statements (including 3 open-ended questions) that assess nine dimensions of organizational innovative climate: challenge $\&$ involvement, freedom, trust / openness, idea time, playfulness / humor, conflict, idea support, debate, and risk-taking. The nine dimensions are scored on a scale from 0 to 300 . Each of the nine dimensions has five to seven constituent items.

\section{The Company and the Participants}

\subsection{The company}

The case company is a Saudi oil company and a world leader in exploration, production, refining, distribution, shipping and marketing. The company is a state-owned oil company of the Kingdom of Saudi Arabia, manages more than 113 oil and gas fields in Saudi Arabia. It is the world's fourth-largest gas reserves, with 282.6 trillion cubic feet and world's top exporter of natural gas liquids. The average daily crude production in 2012 was 9.5 million barrels per day and the total oil production for the year was 3.5 billion barrels, about one in every eight barrels of the world's crude oil production. The company headquarter is in Dhahran and its operations span the globe through Saudi Arabia, North America, Europe and Asia. By December 2012, the company has more than 54,000 employees across Saudi Arabia, North America, Europe and Asia. The company is putting innovation and creativity as one of its priority.

The company organizational chart was studied and analyzed. The technology management division, one of the main company's divisions, was selected as the representative sample of the company. This division consists of two groups and one department: the innovation and knowledge management group, the intellectual assets management group, and the consulting services department. The sample of the study 
included all the 45 employees in the selected divisions' two groups and the department. They consisted of all the 15 employees from the innovation and knowledge management group; all 13 employees from the intellectual assets management group; and all the 17 employees from the consulting services department.

\subsection{Characteristics and distribution of the participants}

The total number of distributed questionnaires was 45 and the number of valid returned questionnaires was 42 with a response rate of $93.3 \%$. The profile of the respondents is looked upon in terms of job title, age, gender, educational level, and length of stay in the company and in current position. The analysis of the data shows that most of the employees who participated in this research were engineers $(88.1 \%)$, the others $(11.9 \%)$ were non engineers, such as: assistant control advisor (2.4\%) contract advisor $(2.4 \%)$ cost group (2.4\%) pipeline consultant (2.4\%), PQP analyst $(2.4 \%)$. The mean age of the participants was 38 years old with a range from 23 to 53. Only two of the respondents were females while forty of the responses were males. The respondents were categorized according to their educational level; four were PhD holders, 13 Master holders, 4 PG degree holders, 19 Bachelor degree holders and 2 College/ two years degree holders. $11.9 \%$ of respondents have more than 20 years in the company while $42.9 \%$ spent from 10 to 20 years, $26.2 \%$ spent from $5-10$ years, $7.1 \%$ had service from 2-5 years, $7.1 \%$ from 7 months to a year and $2.4 \%$ had service for 6 months or less. The number of years of service in the currents position was also obtained. $11.9 \%$ of the respondents spent from 10 to 20 years in their current position, $26.2 \%$ from $5-10$ years, $21.4 \%$ from $2-5$ years, $11.9 \%$ from 7 months to one year, and $14.3 \%$ had service for 6 months or less. The analysis indicates that the majority of the respondents are knowledgeable enough to the climate of the company; it also indicates the maturity of the respondents particularly in terms of experience; and that the majority are knowledgeable enough to the climate of the company, specifically in terms of its innovation and technology.

\section{Assessment of the Innovation Climate in the Company}

The respondents were asked to respond to the extent to which each one of the 53 statements is applicable in their organization. Each one of the nine climate dimensions has five to seven statements. The respondents rated each of these statements. Table (1) shows the results of how the respondents assess their climate for technological innovation within their current work environment. The resulted score for each dimension was ranging from 0 to 300 . The higher the score in the 8 dimensions (challenge and involvement, freedom, trust/Openness, idea time, idea support, risk taking, playfulness \& humor, and debates) means the better climate and for one dimension (conflicts) the less score reflects better climate. The overall scores for each dimension were calculated. Table (2) shows the mean and standard division calculated for each dimension of the innovation climate for the 42 participants.

The average scores represent the respondents' assessment of the extent to which the behaviors described in each dimension are present in their company's climate. The 
results reflect the average score and level of application, as a percentage, for each dimension of the innovation climate in the company and are illustrated in Figures 1 and 2. The results revealed that the debate comes as the most applied dimension with $70 \%$, the two dimensions of idea support and challenge / involvement are applied in the company at the same level of $67 \%$, the trust / openness innovation dimension is applied with $59 \%$, freedom is applied with $57 \%$, idea time with $56 \%$, playfulness / humor with $52 \%$, risk taking with $50 \%$ and conflict -which is a negative dimension- is applied with $46 \%$.

Table 1. Assessment of the technological innovation climate dimensions by each respondent

\begin{tabular}{|c|c|c|c|c|c|c|c|c|c|}
\hline Dimension & 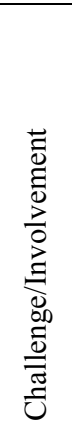 & 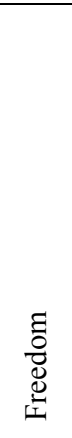 & 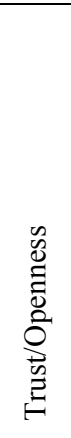 & 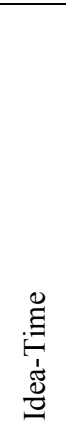 & 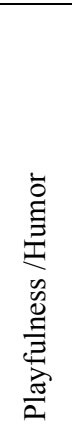 & 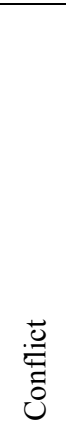 & 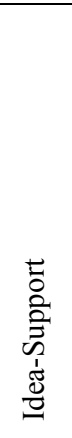 & 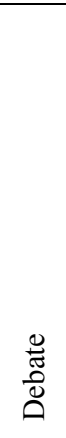 & 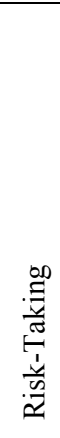 \\
\hline 1 & 86 & 200 & 180 & 133 & 167 & 100 & 180 & 167 & 120 \\
\hline 2 & 171 & 67 & 240 & 67 & 117 & 67 & 140 & 167 & 80 \\
\hline 3 & 71 & 33 & 20 & 83 & 17 & 250 & 120 & 200 & 100 \\
\hline 4 & 129 & 150 & 100 & 117 & 117 & 83 & 220 & 183 & 100 \\
\hline 5 & 286 & 183 & 300 & 250 & 217 & 33 & 280 & 233 & 200 \\
\hline 6 & 229 & 200 & 220 & 217 & 167 & 200 & 220 & 217 & 180 \\
\hline 7 & 186 & 233 & 240 & 250 & 200 & 217 & 260 & 167 & 180 \\
\hline 8 & 214 & 167 & 280 & 233 & 167 & 250 & 200 & 233 & 220 \\
\hline 9 & 214 & 183 & 160 & 200 & 217 & 167 & 200 & 217 & 160 \\
\hline 10 & 200 & 250 & 200 & 217 & 250 & 200 & 220 & 250 & 240 \\
\hline 11 & 200 & 133 & 200 & 50 & 50 & 83 & 120 & 267 & 60 \\
\hline 12 & 214 & 133 & 160 & 100 & 133 & 83 & 300 & 267 & 100 \\
\hline 13 & 286 & 233 & 100 & 150 & 133 & 233 & 220 & 267 & 240 \\
\hline 14 & 143 & 150 & 160 & 150 & 83 & 200 & 120 & 117 & 100 \\
\hline 15 & 171 & 217 & 120 & 167 & 133 & 217 & 180 & 183 & 160 \\
\hline 16 & 214 & 217 & 220 & 200 & 217 & 183 & 200 & 183 & 160 \\
\hline 17 & 214 & 200 & 240 & 217 & 200 & 217 & 240 & 233 & 160 \\
\hline 18 & 200 & 200 & 220 & 217 & 200 & 200 & 220 & 217 & 140 \\
\hline 19 & 214 & 233 & 240 & 183 & 267 & 217 & 160 & 183 & 180 \\
\hline 20 & 243 & 183 & 220 & 217 & 217 & 233 & 220 & 250 & 200 \\
\hline
\end{tabular}




\begin{tabular}{|c|c|c|c|c|c|c|c|c|c|}
\hline Dimension & 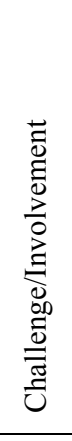 & 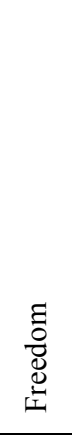 & 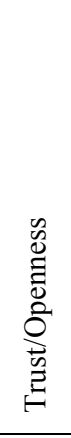 & 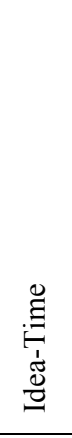 & 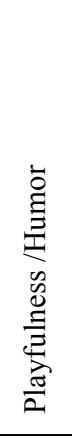 & 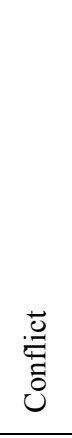 & 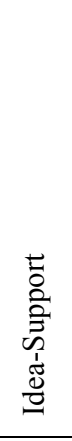 & $\begin{array}{l}0 \\
\text { ज̃ } \\
\text { Dे } \\
\text { 0. }\end{array}$ & 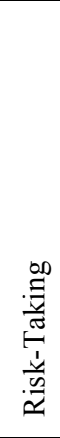 \\
\hline 21 & 186 & 167 & 200 & 200 & 217 & 200 & 180 & 250 & 220 \\
\hline 22 & 171 & 150 & 200 & 217 & 183 & 233 & 220 & 250 & 200 \\
\hline 23 & 286 & 150 & 280 & 133 & 167 & 0 & 280 & 200 & 100 \\
\hline 24 & 271 & 233 & 160 & 200 & 167 & 133 & 240 & 200 & 160 \\
\hline 25 & 286 & 217 & 140 & 250 & 150 & 100 & 240 & 250 & 140 \\
\hline 26 & 14 & 33 & 0 & 0 & 17 & 67 & 0 & 33 & 0 \\
\hline 27 & 243 & 167 & 160 & 183 & 183 & 100 & 280 & 200 & 120 \\
\hline 28 & 171 & 133 & 80 & 133 & 100 & 67 & 160 & 133 & 60 \\
\hline 29 & 143 & 117 & 100 & 133 & 117 & 133 & 160 & 183 & 100 \\
\hline 30 & 271 & 283 & 300 & 250 & 183 & 17 & 220 & 250 & 140 \\
\hline 31 & 186 & 117 & 120 & 100 & 100 & 100 & 140 & 183 & 100 \\
\hline 32 & 186 & 150 & 160 & 100 & 183 & 283 & 160 & 200 & 180 \\
\hline 33 & 200 & 133 & 180 & 100 & 117 & 67 & 200 & 217 & 140 \\
\hline 34 & 257 & 200 & 220 & 233 & 100 & 100 & 280 & 250 & 160 \\
\hline 35 & 229 & 183 & 200 & 200 & 200 & 150 & 260 & 233 & 160 \\
\hline 36 & 243 & 183 & 160 & 200 & 150 & 83 & 200 & 183 & 160 \\
\hline 37 & 157 & 117 & 100 & 183 & 150 & 67 & 180 & 167 & 120 \\
\hline 38 & 200 & 200 & 180 & 150 & 100 & 83 & 260 & 200 & 160 \\
\hline 39 & 157 & 117 & 120 & 133 & 100 & 117 & 160 & 200 & 200 \\
\hline 40 & 186 & 133 & 240 & 133 & 167 & 50 & 160 & 283 & 140 \\
\hline 41 & 186 & 217 & 180 & 250 & 233 & 183 & 240 & 300 & 240 \\
\hline 42 & 271 & 200 & 160 & 200 & 200 & 50 & 200 & 250 & 200 \\
\hline
\end{tabular}

Table 2. Means and Standard Deviations of the Technological Innovation Climate Dimensions

\begin{tabular}{ccccc}
\hline $\mathbf{N}$ & Dimentions & $\mathbf{N}$ & Mean & Std. Deviation \\
\hline 1 & Challenge \&Involvement & 42 & 199.66 & 58.476 \\
\hline 2 & Freedom & 42 & 170.63 & 53.951 \\
\hline 3 & Trust \& Openness & 42 & 177.62 & 67.311 \\
\hline
\end{tabular}




\begin{tabular}{ccccc}
\hline $\mathbf{N}$ & Dimentions & N & Mean & Std. Deviation \\
\hline 4 & Idea Time & 42 & 169.05 & 61.107 \\
\hline 5 & Playfulness and Humor & 42 & 155.95 & 57.948 \\
\hline 6 & Conflict & 42 & 138.49 & 75.033 \\
\hline 7 & Idea Support & 42 & 200.95 & 57.075 \\
\hline 8 & Debate & 42 & 209.92 & 48.704 \\
\hline 9 & Risk-taking & 42 & 149.52 & 53.051 \\
\hline
\end{tabular}

$N=$ number of respondents.

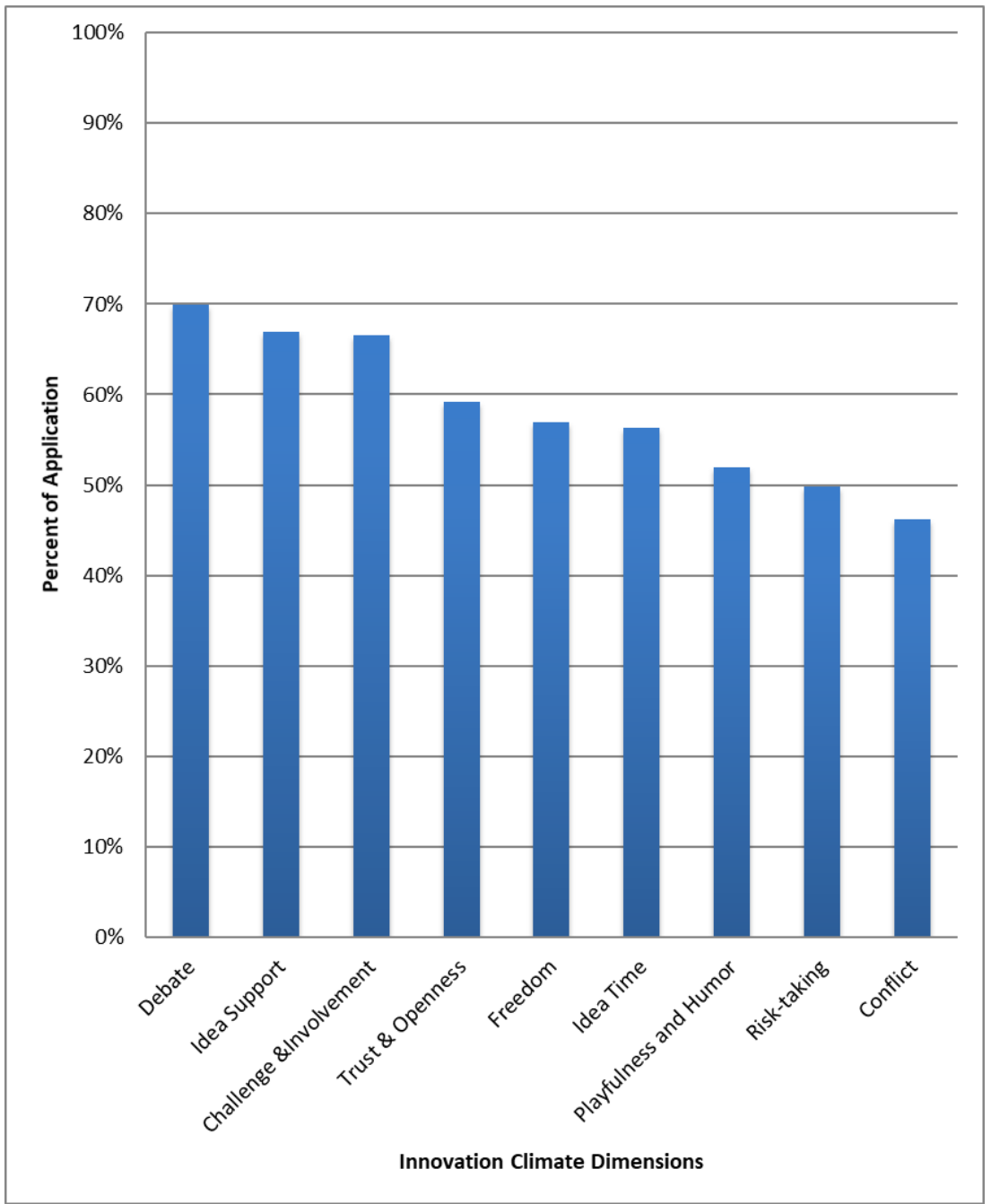

Fig. 1. Application levels of the technological innovation climate dimensions 


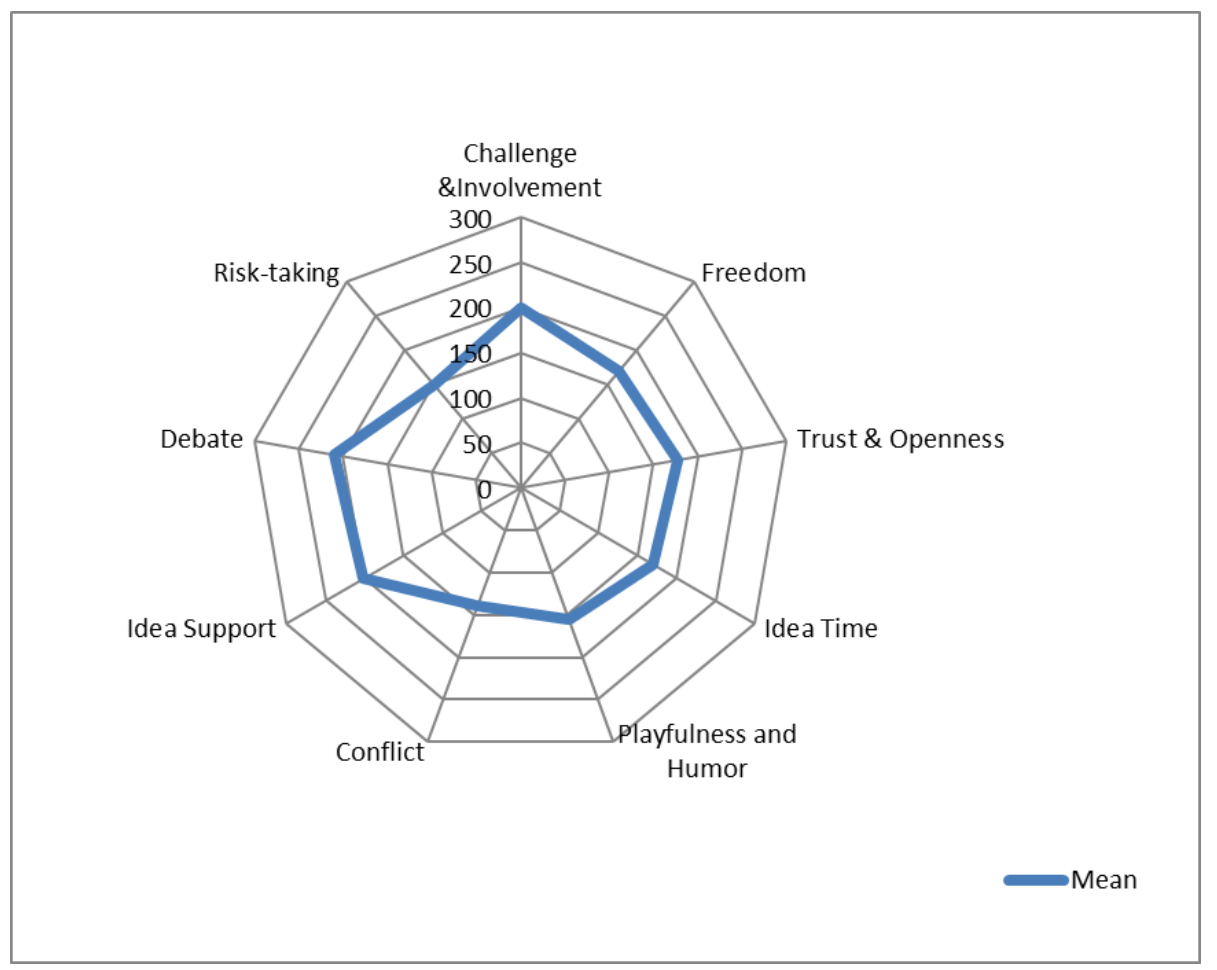

Fig. 2. Assessment of the company's innovation climate

\section{$6 \quad$ Results, Analysis and Discussion}

\subsection{Debate}

Debate means the occurrence and open disagreement between viewpoints, ideas, experiences and knowledge. In the debating situation, many different voices and points of view are exchanged and encouraged. In short it is the exchange of viewpoints, ideas, experiences and knowledge openly. Debate reflects a more productive climate as many voices are heard and people are keen on putting forward their ideas. The main characteristics of debate are: focuses on issues and ideas not on people and their relationships; involves the productive use and respect for diversity of perspectives and points of view; involves encounters, exchanges or clashes among viewpoints, ideas and differing experiences and knowledge. The results showed that the debate dimension obtained the highest score in the company's innovation climate and is applied with $70 \%$. This indicated that the respondents discuss effectively with diversity and sharing opinion in positive ways. However, the dimension could reach the very high position. The consensus opinion of the participants showed that when the score on the debate dimension is too low: employees follow authoritarian patterns without questioning, and they constantly complain about the way things are rather than how they can improve the situation. However, the participants also conceded that if the open debate 
is too high it is likely to exercise one or more of the following: employees focusing more on their individual goals and ignoring the company's goals; more talking than working.

\subsection{Idea Support}

Idea support is the way the new ideas are handled, treated and implemented. The way the new ideas are supported and treated will determine the assessment of better or worse the climate for creativity and innovation. The results revealed that the idea support is applied in the company with $67 \%$. When the participants were asked: what is your understanding of a high idea-support? The opinion of the participants showed that their understanding of a high idea-support include the process used to get the ideas implemented is short and effective; employees listen open-handedly and generously to each other; employees give and take ideas, propositions and proposals in a focused and proficient manner; employees are satisfied with their jobs. When the participants were asked: what happens if there is insufficient support for new ideas? The opinion of the participants showed that in this situation the new ideas offered are few and most of them are outside the directions of the company; few ideas are accepted, and very few are implemented. As for the employees in a low idea-support situation the participants agreed that they would be: irritated by the tedious and mind-numbing process used to get ideas to action; frustrated because nothing is getting done; and dissatisfied with their dull jobs.

\subsection{Challenge / Involvement}

Challenge / involvement could be defined as "the level to which employees are not only involved in the organization's everyday operations but also in the organization's longterm goals". More involvement of the employees in the organization's vision, mission, goals, and everyday operations will enhance the climate for creativity and technological innovation. High levels of challenge \& involvement means that: employees find enjoyment and importance in their work, and therefore they devote more energy in their work; employees are inspired and dedicated to contribute to the success of the organization; and the organization's climate has a dynamic, creative and inspiring quality. The results revealed that the application of challenge and involvement in the company is $67 \%$. When the participants were asked: what happens when the challenge and involvement is too low? The opinion of the participants showed that in the situation when challenge and involvement are too low: employees feel alienated and dissatisfied with their jobs; employees general attitude is redundancy, dismissal, and unimportance in work; employees are neither engaged in the organization's everyday operations nor in the organization's long-term goals; employees interactions are boring; employees general attitude is redundancy, dismissal, and unimportance in work; employees often irritated about the future of their organization; and employees general attitude is redundancy, dismissal, and unimportance in work.

\subsection{Trust and openness}

Trust and openness among the organization's employees are how they openly communicate and trust each other. Trust and openness refer to the passionate and emotional security in relationships and interactions. These relationships and 
interactions are considered safe and secure when employees are seen as not only proficient but also sharing a positive set of values. Trust and openness are often associated with employees having high level of independence and autonomy. Trust is the results of individuals' own personality, experience and organizational climate. The results showed that trust and openness is applied in the company with 59\%. The consensus opinion of the participants revealed that low level of trust and openness results in distrust and suspicion, and means that employees are not communicating openly. When trust and openness are too low the creative climate becomes even worst. Employees keep information to themselves behind closed doors; if they have new ideas they fear of having them pinched; their feedback on other employees' new ideas, if any, is minimal and insignificant if any at all. The top and middle management of the organization have a tendency to unfairly allocate organisation's resources among sectors, departments, sections, groups and individuals.

\subsection{Freedom}

In general, freedom in the work environment is the level of independence shown by the employees in the organization. In more details, freedom could be described as the independence in the behavior, activities and actions exercised or utilized by the employees in the organization. High level of freedom implies more perceived autonomy and ability for individual discretion. To make better climate employees need to control over one's work and how to do it. The analysis of the respondents' results showed that freedom is applied with $57 \%$ in the company. The consensus opinion of the participants showed that, in general, strict regulations, procedures, guidelines and roles affect the climate of creativity and innovation in a negative way. Their opinions also showed that the main characteristics of a climate with high level of freedom are: employees are given autonomy in much of their work; they take the initiative to obtain and share data and information, they take decisions about their jobs; they exercise discretion in their daily actions and activities. The participants also revealed that the main characteristics of a work climate with little level of freedom are: employees show very little creativity for proposing better ways of doing their work; they focus too much on the requirements of what they are told to do; employees carry out their work in an officially prescribed methods, they perform all their work within strict role and procedures; and they spend exceptionally long time obtaining permissions, authorizations, and approval. In the work climate with low level of freedom the management style is usually authoritarian and/or bureaucratic. The participants also expressed their concerns about the work climate with too much freedom. Their perception of a climate with too much freedom is characterized by: employees' behavior and actions show no concern to the organization's strategy; and they are not concerned about their organization, they are mainly concerned about themselves.

\subsection{Idea time}

Idea time is the amount of time that is given by the organization to the employees to be used to generate and test new ideas. The concept is that giving the opportunity to stop work in order to generate and test new ideas will result in better innovation climate. Analysis of the results of the respondents showed that the idea time is applied in their company with $56 \%$. When the participants were asked: what happens if there is 
sufficient time and space for generating new ideas? The opinion of the participants showed that when the idea time is high new suggestions that are based on creative ideas are discussed and tested and employees are likely to use these suggestions. When the participants were asked: what happens if there is insufficient time and space for generating new ideas? The participants also stressed that individuals under time pressure are considerably less likely to be creative or innovative. The opinion of the participants revealed that when idea time is low the employees working hour is full and this causes time pressure which makes thinking outside the instructions and routines very difficult. Furthermore, the answers of the participants also revealed that in these situation employees are only concerned with their current tasks; they show an unhealthy level of stress; they see professional development and training as interruptions and hinders to their ability to compete their daily tasks. As for management, they avoid new ideas because they will take time away from the employees with the impact on the completion of their day-to-day work schedules.

\subsection{Playfulness and humor}

Playfulness and humor are when employees have a sense of humor and fun. Low level of fun at work reflect worst climate of creativity and innovation. More relaxed life where jokes and laughter occur often is enhancing the climate of creativity and innovation. The respondents revealed that the playfulness and humor dimension is applicable with $52 \%$ in their company.

\subsection{Risk taking}

Risk taking is meant to be the level of tolerance of uncertainty and ambiguity in the workplace. Both individual characteristics and organizational climate influence perceptions of risk and the tendencies to avoid, accept or seek risks. This dimension had the minimum score among all the nine dimensions of innovation climate with a percentage of application of $50 \%$. This reflects the respondents' tendency to avoid failure and loss of financial and other resources. The opinion of the participants showed that when risk taking is too low: there is a general culture of caution, carefulness and hesitant mentality. The dominant behaviour of employees is to be on the "safe side"; this is often done by setting up committees and by covering themselves in many ways before making a decision. In general, employees complain about boring, low-energy jobs and are frustrated by a long, tedious process used to get ideas into action. The inevitable consequences of this behaviour are that employees offering very few ideas that are outside of what is considered safe. On the other hand, the consensus opinion of the participants revealed that in a high risk-taking climate: employees can take new initiatives when the outcomes are not completely known or certain; employees can take decisions even when they do not have full information. However, the participants revealed that if there is too much risk taking: the general feeling in the organisation's climate is that there are too many ideas floating around but few are approved and almost nothing is done; individuals do not feel they need a buy-in from others on their team and therefore there is no teamwork and the work climate is dominated by many loners doing their own things. 


\subsection{Conflict}

Conflicts in an organization refer to the presence of personal, interpersonal or emotional tensions. All organizations have some level of personal tension. Conflict is a negative dimension; high score in the conflict dimension means high personal and emotional tension. According to Tidd \& Bessant (2013) conflicts can occur over: tasks, processes or relationships. Task conflicts focus on disagreements about the goals and contents of work, the "what" needs to be done? And "why" to be done? Process conflicts are around "how" to achieve a task? Relationship conflicts are more emotional; they are characterized by hostility and anger and are generally energy-sapping and destructive. They also stated that some task and process conflicts are constructive; they might help to avoid groupthink, consider more diverse opinions and alternative strategies. However, task and process conflict only have a positive effect on performance in a climate of openness and collaborative communication, otherwise it can degenerate into relationship conflict or avoidance. The respondents' results reflected that there is a conflict in their work environment with $46 \%$. When the participants were asked: what is the most important one factor contributing to the creation of a very high level of conflict in the work environment and the creative climate? The opinion of the participants revealed that when a very high level of conflict exists too many incompetent employees are rooted in an exceptionally high hierarchical organizational structure. Their incompetence coupled with their strong desire to keep their undeserved positions makes them create, generate, cause and implement a deliberate conflict climate in order to survive. The opinion of the participants also showed that the characteristics of the climate when the level of conflict is too high are: the work climate is characterized by open aggression, plots and traps, information hoarding, the general climate is dominant by groups and individuals that dislike each other, and even character assassination are not uncommon in the life of the organisation with too high level of conflicts. When the participants were asked: what are the characteristics of the work environment and creative climate when the level of conflict is too low? The opinion of the participants showed that when the level of conflict is too low: the work climate is usually characterized by individuals who lack any signs of creativeness, inspiration or encouragement; employees are not fascinated in or attracted to their jobs; management style is more about "telling" not participating or even selling.

\section{Comparing the Company Results with International Norms}

Comparing the result of innovation climate assessment with a benchmark or international norms will provide better understanding of the organization's ability and situation. Isaksen and Tidd (2006) published scores for the nine dimensions of innovative climate that are assessed by the SOQ and represent innovative, average and stagnated organizations. They explained that organizations were categorized as innovative, average, and stagnated based on their product performance and commercial success. Innovative organizations developed more new products and services, moved them to the marketplace quickly, and commercially successful overall. Stagnated organizations were unable to control development of new products and services, had difficulty getting them to market in a timely and cost-effective manner, and 
commercially in trouble. Average companies fell in the middle. Several previous studies in innovation climate (Bakkar, 2003; Parrish, 2004; Senekal, 2007) have used the international norms from Creative Problem Solving Group to compare the results of their studies.

Table (4) shows the results of the innovation climate dimensions of the Saudi company together with the international innovative, average and stagnated organizations. The results, as illustrated in Figure (3) show that the Saudi company has better scores than the innovative organization in three dimensions: idea time, idea support and debate; and is equal to innovative organizations in one dimension, the trust / openness dimension. The results also revealed that the Saudi company is more than the average organizations and less than the innovative organizations in two dimensions, the challenge / involvement and risk taking dimensions. Also the Saudi company is less than the average organizations in the three dimensions of: freedom, playfulness / humor, and conflict. It can therefore, be concluded that the Saudi company could be categorized as an innovative company in the four dimensions of: idea time, idea support, trust / openness and debate. It could be categorized as average innovative company in the two climate dimensions of challenge / involvement and risk taking. However, the company is categorized as stagnated company in the dimensions of freedom, playfulness / humor and conflict; these results are illustrated in Table (5).

Table 4. Means of International Organizations Innovation Climate Dimensions and the Saudi company

\begin{tabular}{lcccc}
\hline Innovative Climate Dimensions & Innovative & Average & Stagnated & Saudi Co. \\
\hline Challenge \& Involvement & 238 & 190 & 163 & 199.66 \\
\hline Freedom & 210 & 174 & 153 & 170.63 \\
\hline Trust \& Openness & 178 & 160 & 128 & 177.62 \\
\hline Idea Time & 148 & 111 & 97 & 169.05 \\
\hline Playfulness and Humor & 230 & 169 & 140 & 155.95 \\
\hline Conflict & 78 & 88 & 140 & 138.49 \\
\hline Idea Support & 183 & 164 & 108 & 200.95 \\
\hline Debate & 158 & 128 & 105 & 209.92 \\
\hline Risk-taking & 195 & 112 & 53 & 149.52 \\
\hline
\end{tabular}




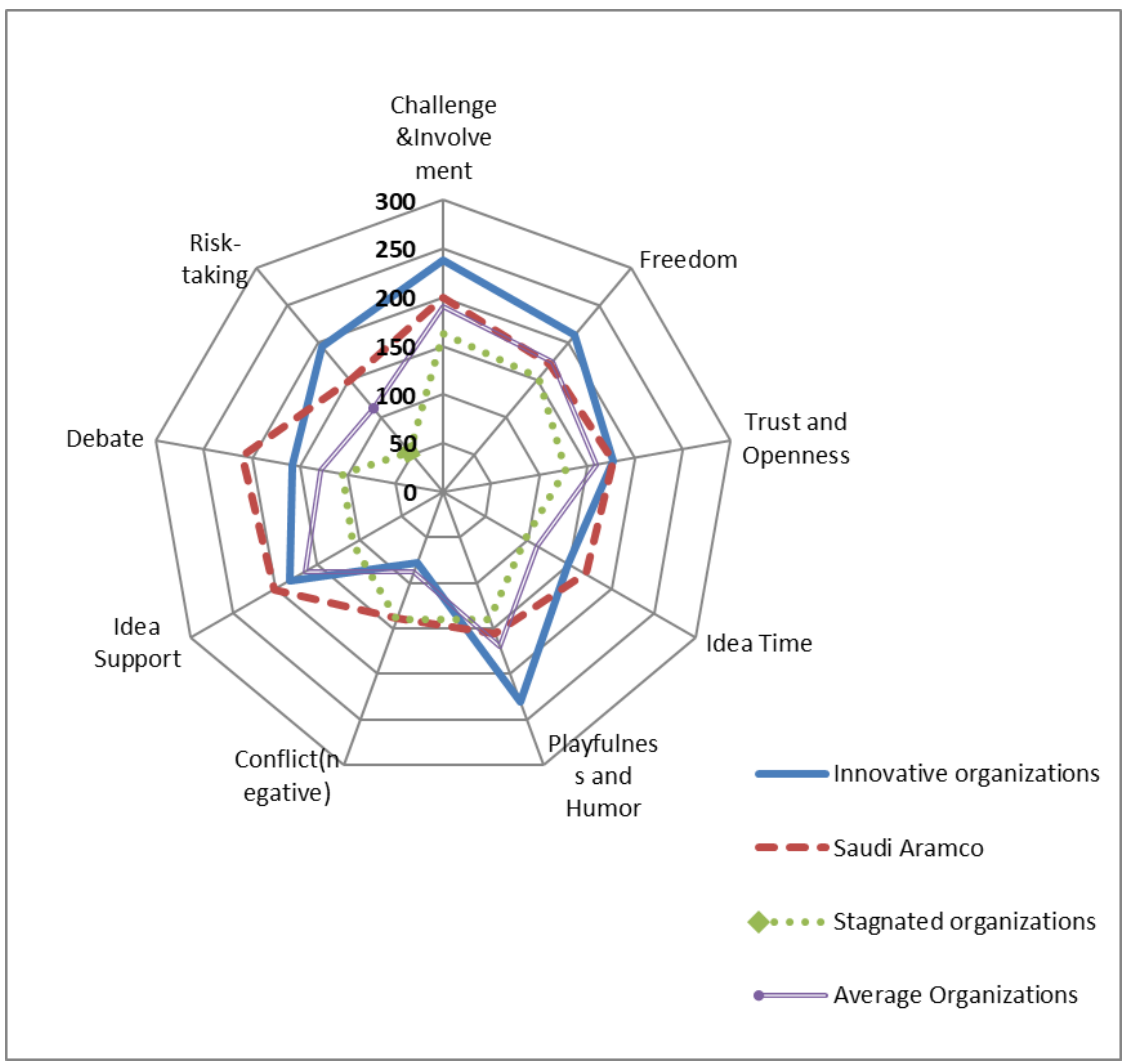

Fig.3. The company innovation dimensions compared with the innovative, average and stagnated organizations 
Table 5. The assessment results in relation to the three categories: innovative, average and stagnated organizations

\begin{tabular}{|c|c|c|c|c|c|c|}
\hline \multirow[b]{2}{*}{ Dimensions } & \multicolumn{2}{|c|}{ Innovative } & \multicolumn{2}{|c|}{ Average } & \multicolumn{2}{|c|}{ Stagnated } \\
\hline & $\begin{array}{l}\text { Better than } \\
\text { innovative }\end{array}$ & $\begin{array}{l}\text { Same as } \\
\text { innovative }\end{array}$ & $\begin{array}{c}\text { Better } \\
\text { than } \\
\text { average }\end{array}$ & $\begin{array}{l}\text { Same as } \\
\text { Average }\end{array}$ & $\begin{array}{l}\text { Better than } \\
\text { stagnated }\end{array}$ & $\begin{array}{l}\text { Stag- } \\
\text { nated }\end{array}$ \\
\hline $\begin{array}{l}\text { Challenge/ } \\
\text { Involvement }\end{array}$ & & & $*$ & & & \\
\hline Freedom & & & & & $*$ & \\
\hline $\begin{array}{l}\text { Trust/ } \\
\text { Openness }\end{array}$ & & $*$ & & & & \\
\hline Idea Time & $*$ & & & & & \\
\hline $\begin{array}{l}\text { Playfulness / } \\
\text { Humor }\end{array}$ & & & & & $*$ & \\
\hline $\begin{array}{l}\text { Conflict } \\
\text { (negative) }\end{array}$ & & & & & $*$ & \\
\hline Idea Support & $*$ & & & & & \\
\hline Debate & $*$ & & & & & \\
\hline Risk-taking & & & $*$ & & & \\
\hline $\begin{array}{l}\text { Total of the } \\
\text { sub categories }\end{array}$ & 3 & 1 & 2 & & 3 & \\
\hline $\begin{array}{l}\text { Category } \\
\text { Total }\end{array}$ & & & & & 3 & \\
\hline
\end{tabular}

\section{Strengths and Weaknesses of the Company in Relation to Intemational Norms}

To statistically test the strengths and weaknesses of the innovation climate of the Saudi company a one-sample $t$ test is conducted to find statistically the significant deference between the Saudi company and the innovative organizations, and the significant deference between the Saudi company and the stagnated organizations. The t-test is used to determine if two sets of means are significantly different from each other (Rosenthal, 2011). The one sample t-test is used because the populations of the innovative and stagnated organizations are not available. When the difference is reliable or real it means significant difference between the Saudi company and the international innovative organizations in their innovation climate at the 0.01 level of alpha. The lower the value of alpha it is claimed that the result is statistically significant. If the dimension score of the Saudi company is statically equal or higher than the innovative dimension score, this is considered as strength point and if it is less or equal to a stagnated dimension score, this is considered as weakness. 


\subsection{Comparing the company with innovative organizations}

Table 6 shows the means of the nine dimensions of innovation climate of the company compared with the values of innovative organization using t-test at level of $p=.01$

Table 6. T-test values of comparing means of innovation climate dimensions between the company and the innovative organizations

\begin{tabular}{|l|c|c|c|}
\hline \multirow{2}{*}{ Innovation climate dimensions } & \multicolumn{3}{|l|}{ Innovative organizations } \\
\cline { 2 - 4 } & T test & Df & $P$ \\
\hline Challenge / involvement & -4.249 & 41 & 0 \\
\hline Freedom & -4.729 & 41 & 0 \\
\hline Trust / openness & -0.037 & 41 & 0.971 \\
\hline Idea time & 2.232 & 41 & 0.031 \\
\hline Playfulness / humor & -8.281 & 41 & 0 \\
\hline Conflict & 5.225 & 41 & 0 \\
\hline Idea support & 2.038 & 41 & 0.048 \\
\hline Debate & 6.909 & 41 & 0 \\
\hline Risk taking & -5.555 & 41 & 0 \\
\hline $\boldsymbol{P < 0 . 0 1}$ & & &
\end{tabular}

The results showed that the company is significantly less than the values of innovative organizations in four dimensions: challenge / involvement, freedom, playfulness / humor, and risk taking. The results also showed that there was no significant difference between the company and innovative organizations in the three dimensions of: idea time, idea support, and trust / openness. This means that the company's levels are similar to the innovative organizations in theses dimensions. The main results from the t-test could be summarized in three points. a) The company's strongest innovation climate dimension is debate because it is significantly higher than innovative organization. b) It has three strong dimensions: idea time, idea support, and trust/openness because there are no statically significant differences between them and those of the innovative organizations. c) The remaining dimensions of challenge / involvement, freedom, playfulness/humor and risk taking are significantly less than innovative organizations, but still higher than the stagnated organizations.

\subsection{Comparing the company with stagnated organizations}

The means of each of the dimensions of the technological innovation climate in the Saudi company is compared with the innovation climate values of stagnated organizations using a one-sample t-test. The results are shown in Table (7), which shows that the means of the Saudi company are significantly higher than the stagnated organizations at level of $\mathrm{p}<0.01$ in the six dimensions of: challenge / involvement, trust / openness, idea time, idea support, debate, and risk taking. This means that the 
company is significant higher than stagnated organizations in these dimensions. Whereas, there is no significant difference between the Saudi company and the stagnated organizations in the three dimensions of: freedom, playfulness / humor, and conflict. This means that the company and the stagnated organizations are similar in these dimensions. Therefore, the main results from comparing the company with stagnated organizations using the $t$ test showed that the Saudi company weaknesses in the innovation climate dimensions are freedom, playfulness / humor, and conflict because there is no significant difference between the Saudi company and the stagnated organizations.

Table 7. $T$ test values of comparing means of innovation climate dimensions between the company and the stagnated organizations

\begin{tabular}{|l|c|c|c|}
\hline \multirow{2}{*}{ Innovation climate dimensions } & \multicolumn{3}{|c|}{ Stagnated organization } \\
\cline { 2 - 4 } & T test & df & P \\
\hline Challenge \& involvement & 4.063 & 41 & 0 \\
\hline Freedom & 2.118 & 41 & 0.04 \\
\hline Trust \& openness & 4.777 & 41 & 0 \\
\hline Idea time & 7.641 & 41 & 0 \\
\hline Playfulness \& humor & 1.784 & 41 & 0.082 \\
\hline Conflict & -1.13 & 41 & 0.897 \\
\hline Idea support & 10.554 & 41 & 0 \\
\hline Debate & 13.961 & 41 & 0 \\
\hline Risk taking & 11.791 & 41 & 0 \\
\hline P<0.01 & & & \\
\hline
\end{tabular}

From the above results of the two t-tests, it could be concluded that the debate dimension is ranked higher than the innovative organizations and hence its measured level is considered too high. The dimensions of idea time, idea support, and trust / openness are considered as strong dimensions as their scoring are in the range of at the same level as the innovative organizations. While the innovation climate dimensions of freedom, playfulness / humor, and conflict are considered as weak dimensions as they are at the same level of stagnated organizations. The remaining dimensions of challenge / involvement and risk taking are considered as average strength dimensions. Table (8) summarizes the strengths, average and weaknesses of the technological innovation climate dimensions of the company. 
Table 8. Strengths and weaknesses of the company's technological innovation climate

\begin{tabular}{|c|c|c|c|}
\hline $\begin{array}{c}\text { Too high } \\
\text { Dimensions }\end{array}$ & Strong dimensions & $\begin{array}{c}\text { Average } \\
\text { Dimensions }\end{array}$ & $\begin{array}{c}\text { Weak } \\
\text { dimensions }\end{array}$ \\
\hline Debate & $\begin{array}{c}\text { Idea time } \\
\text { Idea support } \\
\text { Trust and openness }\end{array}$ & $\begin{array}{c}\text { Challenge and involvement } \\
\text { Risk taking }\end{array}$ & $\begin{array}{c}\text { Freedom } \\
\text { Playfulness and humor } \\
\text { Conflict }\end{array}$ \\
\hline
\end{tabular}

\section{Recommendations}

a) Two main recommendations to improve technological innovation climate in the company were concluded from the results. First, maintain and sustain the strong dimensions of innovation climate in the company; these are: idea time, idea support and trust/openness. Second, focus to improve the three weak dimensions of freedom, playfulness/humor and conflict; focus to improve the too high dimension of debate; and improve the average dimensions of challenge / involvement and risk taking.

b) Recommendations to improve the too high dimension of debate: In this situation where the debate dimension is too high or at least almost reaching the "too high" position, and in order to keep it high but not too high, the participants recommended to hold structured discussions and affirm commonly held values among employees; and to get the employees involved in interpreting the vision, mission, purpose and goals of the organization.

c) Recommendation to improve challenge / involvement: To improve this situation, the participants recommended getting employees involved in creating or interpreting the vision, mission, objectives, and strategy of the organization. They also expressed that organizations that focus on work challenge rather than formal authority result in creative and innovative climate and organisation systems that provide useful information for subordinates to improve, learn and develop, results in higher levels of creativity and innovations.

d) Recommendation to improve risk taking: The participants recommended the development and continuous improvement of the reward, incentive, bonus, and promotion systems to encourage cooperation and integration rather than individualism and competition; and the structured formal efforts to help the development of team building.

e) Recommendation to improve conflict: To improve this situation, the participants recommended to scrutinize the organisational structure, identify leaders and high positioned employees who possess the kinds of competencies and qualities that fit the positions requirements, and replace those who do not possess these competencies and qualities. However, the participants recommended that cautious must be taken in order to keep the conflict level in the high level and not to keep reducing it to the low or the too low levels. Therefore, initiative to stimulate and provoke cooperation and integration among key individuals and departments in the organisation must be taken. 


\section{Conclusions}

The Situational Outlook Questionnaire was used to assess nine key dimensions of the technological innovation climate in a Saudi company, one of the largest Oil and Gas companies in the Middle East. The results showed that the extent to which each of the nine dimensions is applied were: debate (70\%); idea support $(67 \%)$; challenge/involvement (67\%); Trust and openness (59\%); freedom (57\%); idea time $(56 \%)$; playfulness/humor (52\%); risk taking (50\%) and conflict (46\%).

The results of the company were compared with published norms of international organizations. The climate of the Saudi company was categorized as innovative in the four dimensions of idea time, idea support, trust and openness, and debate; categorized as average innovative in the two dimensions of challenge and involvement, and risk taking; and categorized as stagnated company in the three dimensions of freedom, playfulness and humor, and conflict.

The above results were tested using the t-test and the results confirmed that the strengths of the innovation climate of the Saudi company are in the dimensions of: debate, idea time, idea support, and trust/openness. The weaknesses are in the dimensions of freedom, playfulness/humor and conflict.

The recommendations to improve technological innovation climate in the company were concluded from the results. Maintain and sustain the strongest dimensions of innovation climate in the Saudi company: debate, idea time, idea support and trust/openness. Improve the average dimensions of: challenge / involvement and risk taking. Focus to improve the weak dimensions of in the company: freedom, playfulness/humor and conflict.

Acknowledgments. The authors would like to thank the Creative Problem Solving Group, Inc. for allowing them to use the SOQ, to thank the reviewers for their valuable comments and the JIM founding editor for his support and cooperation.

\section{References}

Abdel-Razek, R.H. \& Alsanad, D.S. (2014). "Auditing and comparing innovation management in organizations", Global Journal of Business Research, the Institute of Business and Finance Research, 8 (3), 49-56.

Abdel-Razek, R.H. (2014). "A proposed framework for mapping technological innovation”, Proceedings of the 2014 International Symposium on Business and Management - Fall Session, 12-14 November, 2014, Mejei University, Tokyo, Japan, pp. 377-389.

Abdel-Razek, R.H. \& Alsanad, D.S. (2015). "Evaluation of innovation management in developing countries: a comparative study", Arab Gulf Journal of Scientific Research (AGJSR), Arabian Gulf University, 33 (1), 1-10.

Adolfsson, J., Stojcevski, T., \& Lamskemper, J. (2013). Influence Of Leadership Characteristics On Creative Climate In Research And Development Teams, unpublished executive MBA thesis, Gothenburg University, Sweden.

Alabbas, S., \& Abdel-Razek, R.H. (2016). "Mapping and benchmarking technological 
innovation of three international petrochemical companies", Journal of Innovation Management (JIM), 4 (3), 101-124.

Alsanad, D.S., \& Abdel-Razek, R.H. (2016). "Mapping technological innovation: methodology and implementation", Journal of Review of Business \& Finance Studies, IBFR, 7(1), 59-67.

Amabile, T., Burnside, R. M., \& Gryskiewicz, S. S. (1999). User's Manual for KEY S, Assessing the Climate for Creativity: A Survey from the Center for Creative Leadership, Center for Creative Leadership.

Anderson, N., \& West, M. A. (1996). The team climate inventory: development of the TCI and its applications in team building for innovativeness. European Journal of work and organizational psychology, 5(1), 53-66.

Bakkar, A. A. (2003). Creativity-Enhancement In Media Organizations: A Study Of The Perception Of Journalists And Media Managers In Saudi Arabia, unpublished Ph.D. dissertation, University of Oklahoma Graduate College.

Hoe, S. (2011). Measuring an organization's innovation climate: A case study from Singapore. Development and Learning in Organizations, (25) 6, 1-10.

Hunter, K. Bedel L., \& Mumford, M. (2005). Dimensions of creative climate: a general taxonomy, The Korean Journal of Thinking and Problem Solving, (15) 2, 97-116.

Hunter, S. T., Bedell, K. E., Mumford, M. D. (2007), Climate for creativity: A quantitative review, Creativity Research Journal, 19, 69-90.

Isaksen, S. G., Lauer, K. J., \& Ekvall, G. (1999). Situational outlook questionnaire: A measure of the climate for creativity and change, Psychological Reports, 85(2), 665-674.

Isaksen, S., \& Tidd, J. (2006). Meeting The Innovation Challenge: Leadership For Transformation And Growth. John Wiley \& Sons.

Isaksen, S. G., Ekvall, G. (2013). Psychometrics Of The Current Version Of The Situational Outlook Questionnaire: A Technical Resource For The SOQ. Buffalo, NY: Creative Problem Solving Group - Buffalo.

McAlindon, H. R. (2004). Innovation Climate, Information Technology Leadership in Higher Education, (1), pp.73-82.

Mathisen, G. E., \& Einarsen, S. (2004). A review of instruments assessing creative and innovative environments within organizations, Creativity Research Journal, 16(1), 119-140.

Parrish, E. L. (2004). A Comparative Study Of The Organizational Climate At The Army Materiel Command Regarding Creativity And Change. Unpublished Ph.D. dissertation, Minneapolis, MN: North Central University.

Parther, C. (2010). Managers Guide to Fostering Innovation and Creativity in Teams. Madison, Wisconsin: CWL Publishing Enterprises developed for McGraw Hill.

PriceWaterhouseCooper (2007). Compete \& Collaborate, the 11" Annual Global CEO Survey, New York.

Rosenthal, J. A. (2011). Statistics and Data Interpretation for Social Work. Springer Publishing Company. 
Sanyal, B.C., \& Varghese, N.V.(2006). Research Capacity of Higher Education Sector in Developing Countries. International Institution for Educational Planning, UNESCO.

Siegel, S. M., \& Kaemmerer, W. F. (1978). Measuring the perceived support for innovation in organizations, Journal of Applied Psychology, 63(5), 553-563.

Senekal, E. (2007). The influence of organizational climate on creativity and innovation in a technology firm in South Africa, unpublished Master's thesis, Faculty of Management, the University of Johannesburg.

Tidd, J., \& Bessant, J. (2013). Managing Innovation: Integrating Technological, Market and Organizational Change. John Wiley and Sons, Inc.

UNESCO. (2010). UNESCO Report. United Nations Educational, Scientific and Cultural Organization. Accessed 10 ${ }^{\text {in }}$ January, 2016 from: http://www.unesco.org/science/psd/publications/usr10_arab_states.pdf 